\title{
ASÍ EN PANDEMIA COMO EN LA VIDA: UN ACONTECIMIENTO EN TIRANOS TEMBLAD 2021
}

\author{
In pandemic as it is in life: an event in Tiranos Temblad 2021
}

Assim na pandemia como na vida: um acontecimento em Tiranos Temblad 2021

Fernando Andacht

Profesor Titular, Universidad de la República, Montevideo

fernando.andacht@fic.edu.uy

\begin{abstract}
Resumen
En su casi década de existencia, la serie web Tiranos Temblad(TT) en YouTube cambió la periodicidad aún presente en su título "T. T. Resumen semanal de acontecimientos uruguayos", pero nunca representó "acontecimientos". La edición anual 2020 difundida el 6 de abril, 2021 incluyó signos de la emergencia sanitaria/pandemia. La poética de $T T$ fue siempre reciclar y re-escenificar situaciones banales que aluden o mencionan de algún modo a Uruguay, desde dentro o fuera del país, con conocimiento real o con total ignorancia. Mediante un inconfundible comentario en voice over, TT exhibe un montaje de 'normalemas', videos de YouTube que representan la normalidad. Ahora TT llegó tras un quiebre radical de lo normal. Analizo su estrategia discursiva para representar la ruptura máxima de la normalidad, a causa de la irrupción de un genuino acontecimiento.
\end{abstract}

Palabras clave: Serie web Tiranos Temblad. Acontecimiento. Pandemia

\section{Resumo}

Em quase uma década de existência, a série web Tiranos Temblad (TT) no YouTube mudou sua periodicidade ainda presente no seu título "T. T. Resumen semanal de acontecimientos uruguayos", mas nunca representou "acontecimentos". A edição n anual 2020 difundida no 6 de abril 2021, incluiu signos da emergência sanitária/pandemia. A poética de TT consistiu sempre em reciclar e reencenar situações banais que aludem ou mencionam de algum jeito a Uruguai, do interior ou de fora desse país, com conhecimento real ou com absoluta ignorância. Através de um inconfundível comentário em voice over, TT apresenta uma montagem de 'normalemas', de vídeos de YouTube que representam a normalidade. Agora TT veio depois de uma perturbação radical do normal. Analiso sua estratégia discursiva para representar a quebra máxima da normalidade, a causa da irrupção de um autêntico acontecimento.

Palavras-chave: Série web Tiranos Temblad. Acontecimento. Pandemia.

\section{Abstract}

In almost a decade of existence, the web series Tiranos Temblad (TT) in YouTube changed the frequency still found in its title "T. T. Resumen semanal de acontecimientos uruguayos", however, it never represented "events". The 2020 annual edition released on April 6, 2021 included signs of the sanitary emergency/pandemic. The poetics of $T T$ consisted always in recycling and re-staging banal situations that mention Uruguay or somehow deal with it, from inside or outside the country, with real 
knowledge or with utter ignorance thereo. Through an unmistakable voice over comment, TT displays a montage of 'normalemes', YouTube videos that represent normality. At present, $T T$ arrived after a radical breakdown of normality. I analyze its discourse strategy to represent the greatest breach of normalcy, because of the irruption of an authentic event.

Key words: Tiranos Temblad web series. Event. Pandemic.

\section{UNA SERIE SOBRE ACONTECIMIENTOS SIN ACONTECIMIENTOS}

Aunque habla de la literatura de un refinado escritor, la observación de Sturrock (1986) es útil para estudiar la popular serie web Tiranos Temblad. Resumen semanal de acontecimientos uruguayos (TT, de aquí en adelante): "Borges nunca confundió la literatura con la vida. La literatura es mejor para nosotros que la vida, porque es más interesante, y es más interesante porque ha sido planeada, mientras que la vida es tan descorazonadoramente sin trama." Un modo original, insólito de planear la vida en sus aspectos más banales es precisamente lo que caracteriza y vuelve interesante a TT. Propongo describir la poética de la serie de YouTube como un caso contemporáneo de "la transfiguración del lugar común", pues en términos de Danto (1981, p. 208) TT "hace lo que las obras de arte siempre han hecho exteriorizar un modo de ver el mundo, expresar el interior de un período cultural". Con un formato híbrido del registro documental y de la serie de entretenimiento, TT transfigura la filmación amateur de aspectos triviales del mundo de la vida en una forma literaria inédita. Para entender la atracción duradera que produce TT, en YouTube desde 2012, recurro a otro analista literario en base a materiales que encuentra en esa red social mediática (Carlón, 2020): "En vez de que el arte refleje la vida, la vida se ha alineado con el arte. Al retratarse a si mismo, el arte termino por imitar la realidad" (Eagleton, 2003). Gracias a la ubicua y accesible tecnología para registrar en video momentos que estarían (¿deberían estar?) destinados al olvido, esta serie web produce un insólito catálogo museístico de la banalidad en torno a un único tema: se trata de videos de YouTube que mencionan o muestran, no importa con qué grado de fidelidad o de conocimiento, algo relacionado con el país Uruguay. El impulso universal a filmar sin pausa lo cotidiano lo vuelve un proto-arte, una forma estética salvaje. Un rasgo distintivo de $T T$ es su amorosa exploración de lo banal cotidiano materializado en innumerables videos anónimos subidos a esa red social mediática, la materia prima de la serie. De modo semejante a la estética documentalista brasileño E. Coutinho, quien afirmó que "as pessoas mais comuns têm pouco a perder. Essa é a primeira razão pela qual as pessoas ditas comuns são mais interessantes" (en Frochtengarten, 2009), en TT, el 
creador o curador uruguayo Agustín Ferrando muestra en cada edición de la serie su innegable atracción por la gente y la vida común. El realismo producido por ambos realizadores audiovisuales no rechazaría "La idea de que la vida cotidiana es dramáticamente fascinante (...) simplemente en su ilimitado detalle monótono, es una de las grandes concepciones revolucionarias en la historia humana" (Eagleton, 2003).

Si el fonema es la unidad mínima de sonido con función distintiva del lenguaje verbal, propongo aquí el concepto de 'normalema', que defino como la unidad mínima de representación audiovisual de la normalidad. Los aproximadamente 25 minutos de cada programa de $T T$ consisten en un montaje de normalemas, que transfiguran signos destinados originalmente a un consumo personal y efímero en un artefacto estético, admirable por muchos. Hay dos clases de normalemas, según el criterio que propuse en otro lugar (Andacht, 2017): centrípetos si provienen de uruguayos que viven dentro o fuera del país, y centrífugos, si se originan desde la mirada de extranjeros, ya sea que estén de visita en Uruguay, o desde la lejanía física o la casi completa ajenidad a un conocimiento válido. ${ }^{1}$

La pregunta que motiva mi análisis de los signos de la serie web TT es: ¿qué nos atrae y entretiene en esta creación, luego de una década de conocer casi de memoria su formato tan previsible, con secciones fijas y con la impertérrita voz de su narrador? Mi corpus consiste en la más reciente producción de $T T$, que fue subida a YouTube el 6 de abril de 2021. Hay una primera pista que surge ya al inicio del programa, antes de que oigamos el inconfundible relato del curador A. Ferrando; se trata de un comentario de voice over en inglés cuyo tono entre solemne e irónico hace pensar en una imaginaria Guía del Mochilero Universal: “¡Cuando miras el mapa, es fácil ver que el país Uruguay es una anomalía, no debería existir!" El video muestra un acercamiento al mapa de América del Sur, hasta que se detiene en el pequeño y triangular 'paisito', como denominan a Uruguay sus habitantes, con una mezcla de menosprecio y jactancia negativa (Andacht, 1996), es decir, con el indisimulado orgullo de no tener orgullo (de su propia nación). Cabe destacar que el énfasis del anónimo narrador anglófono contrasta con la monótona y plana tonalidad del voice over del relator estable de TT, un rasgo admirado y central del programa. Muchos de los cientos de miles de visitantes de la edición anual 2020 comentan entusiasmados que ignoraban que el presentador de la semana en el canal de Cartoon Network no es otro que Agustín Ferrando. Esa manera de aplicar en otro formato audiovisual la reconocible estética $T T$ fue el único modo en que su

\footnotetext{
${ }^{1}$ Un recurso humorístico de $T T$ es no sólo incluir videos centrífugos, es decir, que traen comentarios sobre el país o sus costumbres completamente equivocados, sino emitir luego un sello de máxima legitimidad que coloca sobre ese video extranjero, y que reza: "Aprobado por un uruguayo"
} 
creador se benefició económicamente, ya que siempre se negó a comercializar su creación original en YouTube.

La modalidad temporal de esta edición de $T T$ es discretamente indicada al inicio mediante una flecha puesta con el ratón de la computadora; ese signo gráfico se detiene frente a la frase THIS YEAR, escrita con un procesador de texto como Word (Fig. 1a). Luego aparece el tradicional logo: la imagen de un fondo de cielo celeste con nube blanca, el hierático sol de la bandera uruguaya (ver Fig. 1b), y en el medio el nombre completo y ya anacrónico de la serie enmarcado en los laureles, que simbolizan el triunfo o la gloria de quien accede a la victoria en una competencia deportiva, por ejemplo. ${ }^{2} \mathrm{Si}$ hay una victoria indiscutible en $T T$ es la que logra contra el veloz olvido que consumiría cada uno de los normalemas de su montaje, si no hubieran sido rescatados y organizados en la serie.
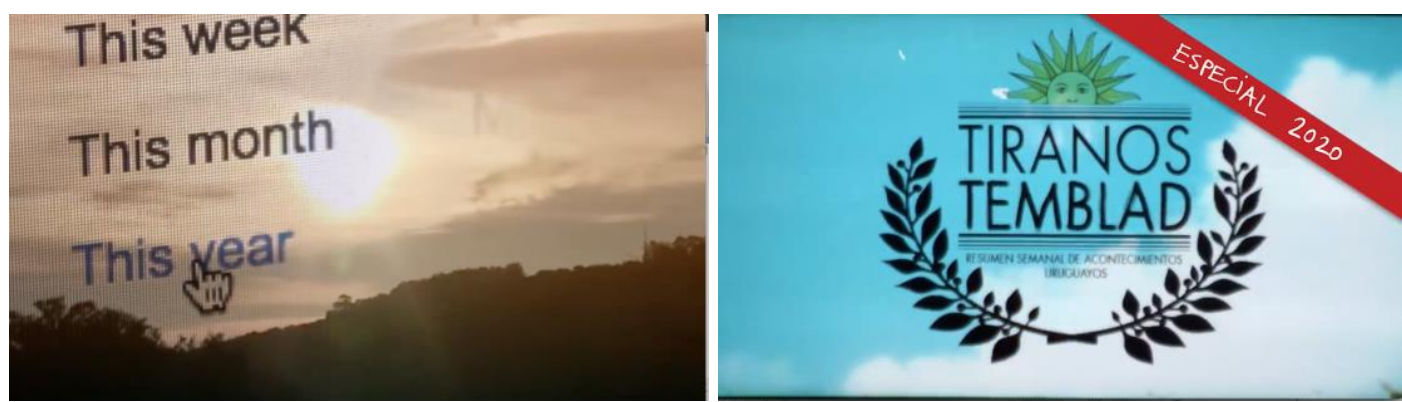

Fig. 1a, 1b - Signos de identidad del programa Tiranos Temblad

\section{LAS ANOMALÍAS DE LA SERIE WEB TIRANOS TEMBLAD}

Vamos a detenernos en tres anomalías que exhibe el nombre de este canal de YouTube. La primera que observamos en $T T$ es que ha conservado su nombre o título original, que fue creado al subir su primer programa a YouTube en diciembre de 2012: Tiranos Temblad. Resumen semanal de acontecimientos uruguayos. Hay un flagrante equívoco al denominar así una serie que no es una entrega semanal desde 2014. Más relevante para este análisis es que el programa $T T$ nunca fue un resumen real de lo sucedido en determinado período de tiempo- una tarea difícil aunque no imposible, si se hubiera adoptado el criterio tradicional de noticiabilidad mediática (Wolf, 1991, p. 216). Los videos con que se construye el collage de cada programa distan mucho de ser noticias, en ningún sentido plausible de esa noción. Pero lo más anómalo es algo que ocupa el centro de su estructura

\footnotetext{
${ }^{2}$ La frase 'Tiranos Temblad' es una estrofa del himno nacional uruguayo. Fue usada durante la dictadura cívicomilitar en ese país (1973-1985), para expresar oposición a ese régimen, poniendo notorio énfasis al cantar esa frase, en los actos públicos.
} 
formal y discursiva, me refiero a la noción misma de 'acontecimiento', como surge claramente, si nos remitimos a tres fuentes tradicionales. Una es la Wikipedia, esa versión moderna y accesible de la Encyclopedia Britannica, nos informa que "El término acontecimiento nombra la alteración azarosa, singular y continua cuyos efectos modifican el sentido de lo histórico, lo social o lo político además de lo cultural." En el margen derecho de la página, vemos una imagen fotográfica del ataque contra las Torres Gemelas de Nueva York, el 11 de setiembre de 2001. La leyenda informa: "Los acontecimientos siempre suelen ser fechas que se recuerden posteriormente debido a que marca una ruptura, un 'antes' y un ‘después' de que sucediera lo acontecido. A menudo son eventos traumáticos.” Nada podría ser más diferente de los normalemas representados en los videos seleccionados para TT.

Si nos atenemos a las definiciones de 'acontecimiento' que registra el Diccionario de la Real Academia, es fácil concluir que no describen en absoluto el material audiovisual que constituye la trama narrativa de TT: a) Cosa que sucede, especialmente cuando es de alguna importancia; b) Suceso importante y programado, de índole social, académica, artística o deportiva. Ni importantes ni planificados, los pequeños rituales y alternativas ínfimas de la interacción social de los videos uruguayo-céntricos de $T T$, se limitan a capturar lo que normalmente pasa desapercibido o que está destinado al consumo personal o familiar, como un viaje turístico.

Otra referencia útil para entender la transgresión flagrante en el uso de la noción de 'acontecimiento' en el título y en la trama narrativa de TT la encontramos en la monografía de Dayan y Katz (1992). Ellos estudian los acontecimientos mediáticos como parte de una "política ceremonial (que) expresa el anhelo por la unidad, la fusión” (1992, p. viii). Ese "anhelo" es ignorado o incluso burlado por el los signos incluidos en cada episodio de TT. Dayan y Katz (1992) explican que para producir esas ceremonias es imprescindible usar "los medios, y exigir atención universalmente para contar un relato primordial sobre los asuntos actuales. Ya que estos son acontecimientos que ponen un halo sobre el televisor y transforman la experiencia de mirar" (p. 1). Hasta el programa que afirma resumir el año 2020, ningún video elegido y montado en $T T$ podría, a priori, concitar la atención universal y simultánea con la cual "narrar un relato fundamental sobre asuntos del presente" (ibid.). Un acontecimiento mediático lo recibe el público como si fuera "una orden para parar sus rutinas cotidianas y unirse a una experiencia de día festivo (...) estos acontecimientos son los principales días festivos de la comunicación masiva" (ibid.). 
Lo único que podría describirse como "una interrupción de la rutina" es la visible carga de afecto del registro audiovisual de momentos íntimos que procuran redimir el instante de su ingreso al olvido: la tensión entre el kairos o tiempo fuerte y el chronos como tiempo olvidable, rutinario (Kermode, 1967). Un ejemplo típico ocurre antes del primer minuto de TT. Con su voz monótona y ajena a todo énfasis, el narrador comenta algo casi inútil, porque lo vemos: "Simón estornudó" $(0 ` 49 ”)^{3}$; en seguida, llega la voz del padre o pariente/filmador, que exclama eufórico: "tu primer estornudo en Uruguay". El niño lo confirma satisfecho, mientras avanza por el corredor que une el avión con el aeropuerto. La llamativa ausencia de emoción positiva o negativa en la voz del narrador de $T T$, en nítido contraste con el ánimo exuberante y positivo del que filma no varía cuando nos relata el inicio de la pandemia en Uruguay. Fuera de un muy pequeño círculo, la familia de Simón, no es admisible considerar ese reflejo fisiológico un 'acontecimiento'. Lo que podría ser un instante tesaurizable por ser el viaje inaugural del niño para conocer a su familia uruguaya, para el público de YouTube no lo es en absoluto. Se trataría entonces de un signo indicial - la marca concreta del traspaso de una frontera - que produce un kairos restringido, ajeno al que puede modificar la rutina de toda la población. Esta versión ligera y filmada de un ritual de pasaje para una persona no posee ningún elemento que pueda interesar al colectivo nacional. Lo que es digno de recordar para alguien, puede bien ser invisible e irrelevante para el resto de una comunidad nacional, y a fortiori, global. La transfiguración de la banalidad de ese momento capturado y subido a YouTube tiene lugar por ser parte de un flujo de normalemas no sólo armado sino narrado de un modo que evita con naturalidad todo juicio negativo. En cada momento de $T T$, hay una plena aceptación de la vida por su pura y simple existencia.

\section{UN REAL ACONTECIMIENTO ROMPE LA CALMA ÁTONA DE TT}

Si no hay resumen ni acontecimientos en $T T$, ¿qué le ofrece a sus cientos de miles de seguidores? La explicación que ofrece un lógico sobre la originalidad de la semiótica de Peirce nos puede ayudar, pues ésta se basa en el acontecimiento. Debrock (1991) propone que lo innovador del modelo semiótico triádico es que se trata de "una metafísica de los acontecimientos (que) comienza desde la innegable premisa de la experiencia de que nada es a menos que algo suceda" (p. 56) Debrock define 'acontecimiento' (event, en el original

\footnotetext{
${ }^{3}$ La cifra colocado entre paréntesis al lado de cada fragmento citado de la serie $T T$ corresponde al minuto y segundo en que éste empieza, o en que se inicia y termina. Ej. 0'49" significa en el segundo 49 de los 25 minutos que aproximadamente tiene este programa de 2021.
} 
inglés) como "un proceso que implica una decisión (que) se resuelve en una diferencia específica que produce una diferencia, que a su vez afecta algo más" (ibid.). Puede afirmarse sin temor a exagerar, que todo lo que acaece, lo que surge de esa decisión ontológica e irreversible produce un antes y después. Y eso vale tanto para el modesto estornudo de Simón (0’52"), como para la declaración de emergencia sanitaria del 13 de marzo de 2020 a la que alude, con el incambiado tono neutro e inseparable de la poética de $T T$, al mostrar acto seguido a una joven colocándose una mascarilla (“Incorporamos los tapabocas”, (0’54”). Para la concepción tradicional, sólo la irrupción globalizada de la pandemia se caracterizaría como un verdadero acontecimiento. En TT, hay una actitud budista de aceptar todo lo que existe por el mero hecho de su existencia. Nada es privilegiado ni merece un especial destaque en su narrativa que tampoco brinda información suficiente para resumir el año 2020. Para entender qué es lo que hace precisamente vamos a mostrar un par de pasajes típicos de la serie, para contrastarlos con la representación de lo que el mundo entero consideró el mayor acontecimiento de ese año, la pandemia de Covid-19.

Un acotado grupo de personas filmadas a propósito reaparece en varios programas de TT. Una de ellas es una anciana cuyo apodo es "la Mamama". Su aparición siempre malhumorada la ha convertido en un personaje esperado por los seguidores de la serie. En 2020, la vemos sentada en la entrada de su casa, cuando se frustra por no ver los relámpagos en el cielo nocturno. Dos veces alguien que la filma le avisa sobre su presencia, pero cuando la Mamama intenta observarlos, ya es tarde (1'04"-09"): "Y la Mamama no pudo ver los relámpagos" (Fig. 2), comenta el relator. No imagino una mejor ilustración de un no-evento, del acontecimiento faltando a su cita con la vida. Sin embargo, su habitual gesto de enojo la convierte en un perfecto emoticón tridimensional de la irritación. Se trata de un realismo plano que nace del esfuerzo de un curador encargado de relevar y montar en un extraño collage los aspectos ínfimos de la vida cotidiana, en una comarca imaginaria que no necesariamente coincide con los límites geográficos del país Uruguay. De cierto modo, se vincula con "realismo sucio" de Raymond Carver, el de Agustín Ferrando es un 'realismo átono', despojado de todo sarcasmo o ironía sobre los seres y momentos reunidos en la serie. 


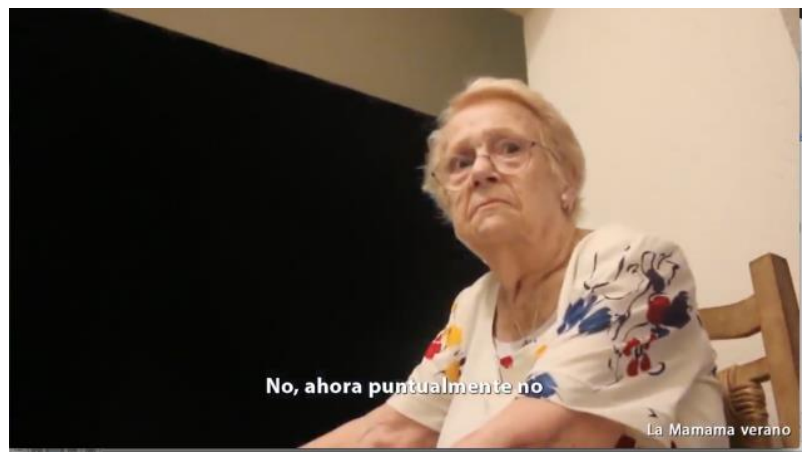

Fig. 2 "Y la Mamama no pudo ver los relámpagos"

Pero ni siquiera el realismo átono e imperturbable de $T T$ pudo ignorar la llegada estruendosa y planetaria de una epidemia convertida en pandemia el 11 de marzo de 2020. Y el modo elegido estuvo acorde a su poética del anti- o no-acontecimiento. Lo hizo del modo más cercano a un no-acontecimiento, a la llegada de otro normalema: "Bajaron un mastelero" (0’31”), mientras vemos que ocurre exactamente esa acción rutinaria y anodina. Sólo los dos segundos que median entre esa escena banal y la siguiente, permiten inferir la llegada de un real acontecimiento: "Empezó una pandemia" ( 0 '34"). La imagen que acompaña ese enunciado desprovisto de toda emoción negativa o positiva es también despojada: la calma inédita de la rambla montevideana filmada desde la altura con un drone un día soleado y sin nubes. La multitud de personas que usual y normalmente aprovecharían un día espléndido del fin del verano para caminar, correr o sentarse a disfrutar del Río de la Plata brilla por su ausencia. La clave desde el análisis que propongo es el montaje y su glosa: al impacto no registrado del inicio del tiempo pandémico le sigue otro normalema: "Un rayo partió una estatua”, que es ilustrado del modo más obvio imaginable (Fig.3a,3b,3c). El tono sereno, casi indiferente de la voz del comentarista, y la serie o enumeración caótica (Spitzer, 1945) son los dos recursos que le restan trascendencia, que minimizan el carácter trágico al primer acontecimiento genuino incluido dentro del formato de la serie $T T$.
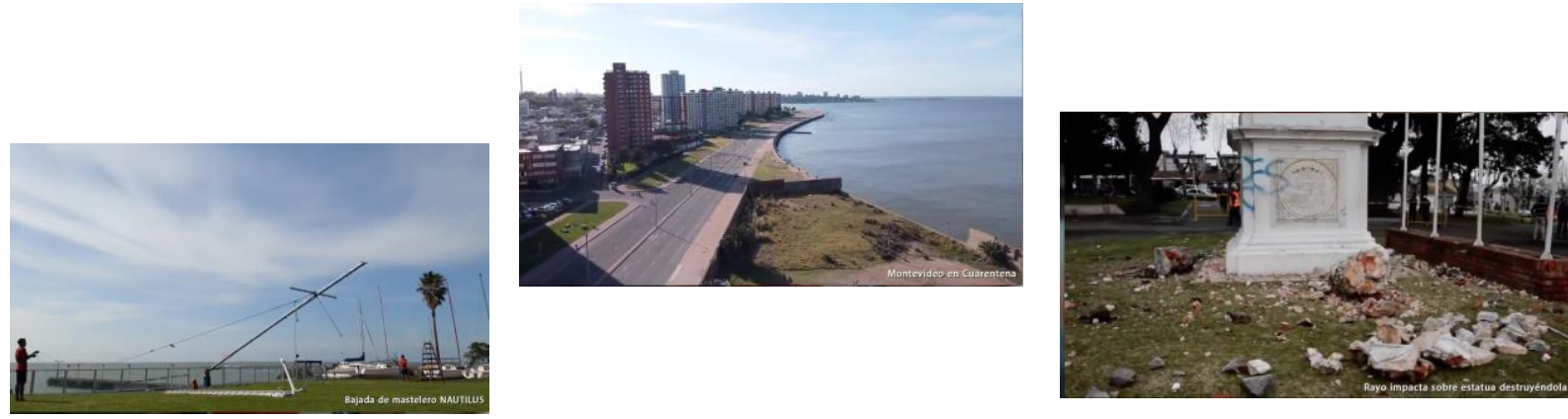

Fig. 3a,3b,3c Secuencia de TT en que irrumpe el acontecimiento de la pandemia 
Apenas medio minuto después, llega el video que ha sido elegido para introducir más formalmente el período pandémico que fue decretado como "emergencia sanitaria", el 13 de marzo de 2020. Ese momento de $T T$ puede describirse como un oxímoron audiovisual, pues mientras el relator acepta que "La protagonista del 2020 fue la pandemia. No hablar de ella en un resumen del año, es imposible" (1'21"- 1'31"), el video muestra una escena que procura con discreción desmentir o amortiguar la gravedad del acontecimiento narrado. Un conjunto de artistas del carnaval uruguayo, tres tamborileros, un abuelo y dos bailarinas despliegan su arte callejero en una calle peatonal de la Ciudad Vieja, la parte más antigua de Montevideo (Fig. 4). Se percibe una mínima alteración en el siempre apacible tono zen del curador/relator de TT: parece un poco más serio, incluso diría solemne. No obstante, su actitud dista mucho del nivel al nivel de alarma productora de ansiedad y de terror constante de los informativos televisivos uruguayos (Andacht, 2020b). Pero es imposible no sentir un sobresalto estético al ver las mascarillas sanitarias blancas y negras que cubren buena parte del rostro de los artistas del carnaval y que ocultan un elemento clave del arsenal expresivo del grupo. Lo más insólito en la narrativa es la justificación que ofrece, con leve tono de disculpa, el narrador, por incluir eso que fue celosamente excluido desde el nacimiento de $T T$, y que constituye un genuino acontecimiento, en un género audiovisual que fue creado para excluirlo de su composición. Lo que imagino oír detrás de la frase efectivamente dicha es: yo hubiera querido tanto no hablar de ese acontecimiento en este resumen, pero eso no fue posible. Definitivamente, no se trata de otro normalema, sino de lo contrario.

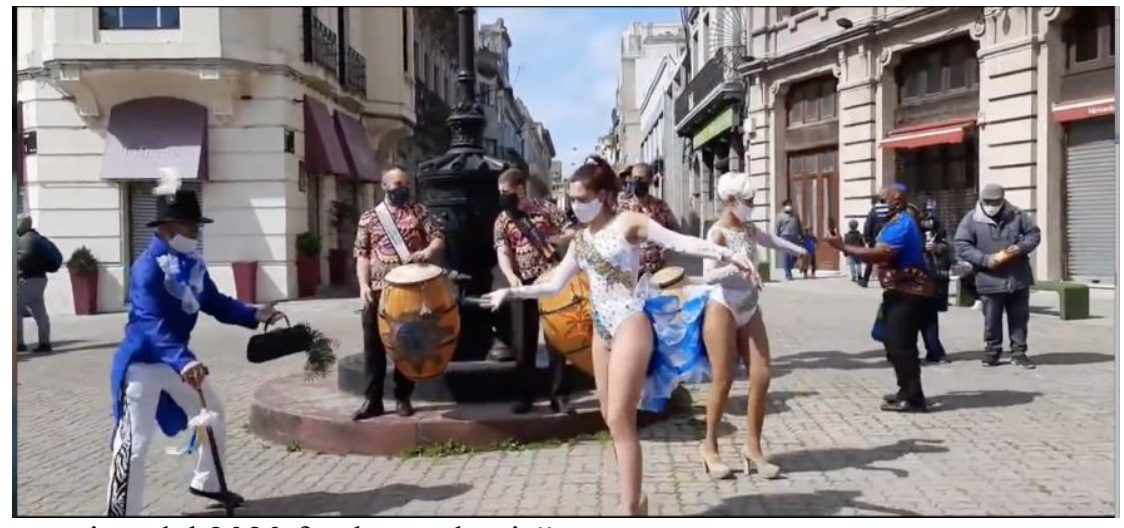

Fig. 4 "La protagonista del 2020 fue la pandemia"

Y en un acto de reflexividad que nos remite a la poética audiovisual de $T T$, el narrador agrega una frase en la que baso mi análisis de la representación de la uruguayidad virtual en YouTube, durante el año en que tantos vivieron con miedo a morir: "Pero voy a intentar 
enfocarme en todo lo otro que también pasó durante todo el año en Uruguay". Mientras el relator y creador de $T T$ pronuncia esa apologia pro arte sua, vemos pasar una ráfaga de hechos mínimos, de varios normalemas característicos de la serie. La primer solución estética que encuentra este curador de lo banal intrascendente que la serie transfigura en material estético admirable al formar parte de su relato es acudir a la mirada centrífuga de los visitantes, y nadie encarna mejor esa categoría humana que el turista. Me detendré en uno de los varios turistas que desfilan en la trama de TT en 2020, pues su actuación natural - aunque ese atributo es dudoso cuando de una performance turística hecha para la cámara se trata - se convirtió en manos del curador en un meme instantáneo.

\section{LA SERIE TT COMO POSIBLE ANTÍDOTO DE LA NUEVA NORMALIDAD}

Cuando oímos la frase sobre "todo lo otro que también pasó durante todo el año en Uruguay", en apariencia parece redundante; nadie que ya ha visto la serie $T T$ tiene la menor duda sobre el turbulento flujo de normalemas narrados con inimitable gracia átona que espera encontrar y disfrutar en cada programa. Pero esta vez la performance vocal que evoca la gracia impávida del cómico del cine mudo Buster Keaton tiene que lidiar con un áspero y brutal acontecimiento definido del modo tradicional. Claro que en la casi década de la serie han ocurrido muchos otros en Uruguay, pero la poética de $T T$ los ha ignorado sistemática y exitosamente. Con la pandemia, esa estrategia ya no es posible, pues atañe al planeta entero. En lugar de incurrir en el escapismo, el narrador le da un amplio espacio en su collage audiovisual a uno de los miles de visitantes veraniegos que trajeron a las costas uruguayas su humanidad hambrienta de sol y mar, cuando nada permitía prever el fin del mundo conocido.

Nada como una celebración totalmente previsible de lo normal, especialmente cuando ya se vivió casi un año de Nueva Normalidad, una frase de sentido contradictorio importada y lanzada el 17 de abril en Uruguay, como eslogan para publicitar el régimen sanitario. " $\mathrm{El}$ 2020 empezó como cualquier otro año, y por eso muchos turistas vinieron a visitarnos" (1'36"). La obviedad del comentario no es tal en el presente contexto, y nos hace pensar en que algo similar podría haber dicho un narrador del norte del mundo sobre el comienzo del otoño de 2001, en la ciudad de Nueva York. Allí también había una multitud de turistas deseosos de aprovechar la agradable temperatura para visitar, entre otros puntos famosos de esa metrópolis. Así se prepara al espectador de la serie web, para conocer a quien resultará ser

\footnotetext{
4 'Por definición, lo que es o se vive como 'normal' nunca puede ser 'nuevo'. Por el contrario, lo normal es algo completamente asimilado, naturalizado, algo de lo cual es necesario olvidarse, para que la vida transcurra normalmente." (Andacht, 2020b, p. 12)
} 
uno de los protagonistas humanos más populares de esta edición anual. Su introducción incluye un dato que aparece escrito en la carátula del video seleccionado (DE EUSKADIZ AL MUNDO): "En este caso, un joven vasco visitó Cabo Polonio" (1'46"). El cartel ubicado abajo a la derecha del video informa sobre el lugar visitado (Uruguay \#7. Un paraíso natural en Cabo Polonio $)^{5}$.

La filmación que al principio se asemeja a un video selfie, revela ser la filmación hecha por un turista compañero. El hombre joven filmado está poseído por la euforia estival, e irá exclamando una serie creciente de banalidades que alcanzan un clímax cuando se zambulle en el océano. Así se produce el humor involuntario que es un sello estilístico de la serie TT: la sucesión de normalemas salvados del olvido por su característica de innegable banalidad, y cuyo único valor, en principio, sería el ser un recuerdo digital que reemplaza la antigua postal o foto impresa y atesorada en el álbum de fotos familiar o personal. Tras la metacomunicación que introduce cada viñeta en la serie, oímos durante casi medio minuto (1'48”- 2'13”) la voz del hombre que vino de España para disfrutar de la versión más agreste de la costa atlántica uruguaya. Luego él reaparecerá como leitmotiv iconográfico de TT. Con sus amplios y enfáticos gestos, el anónimo turista vasco parece querer emular o parodiar la publicidad de un lugar de veraneo, pero en manos del creador de $T T$, el normalema centrífugo ingresó a la categoría de meme (Fig. 5a, 5b).
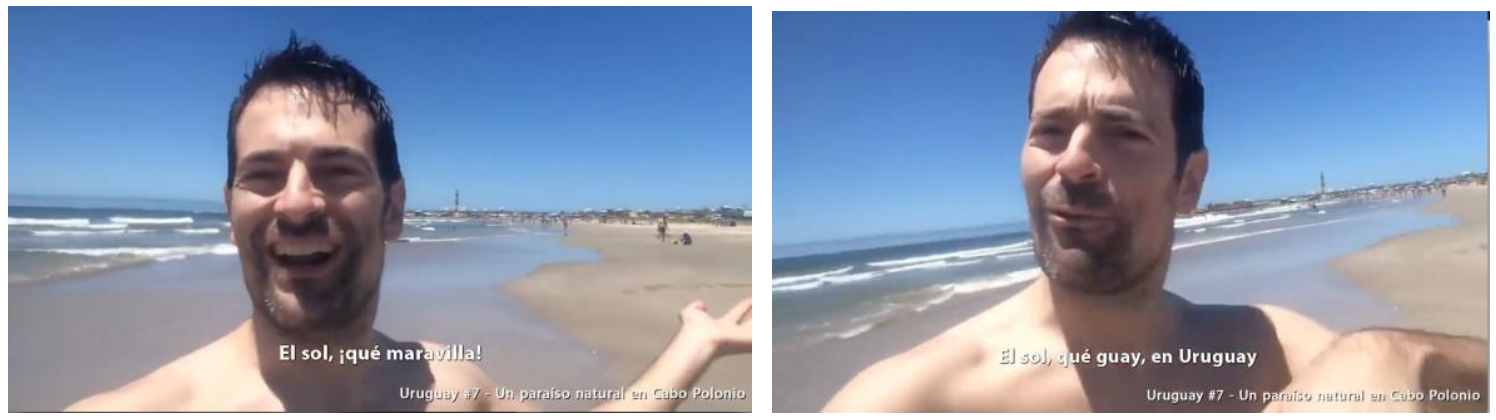

Fig. 5a, 5b "El sol, ¡qué maravilla!” ; ¡El sol, qué guay en Uruguay!”

El turista vasco sonríe fascinado con su propio juego de palabras infantil: "El sol que maravilla. El sol que guay en Uruguay. ¡Si no lo digo reviento! ¡Esto es así!”. Por momentos, se produce la impresión de que él estuviese siendo entrevistado por uno de esos programas de verano, que se dedican justamente a recabar opiniones tan banales como previsibles sobre felices encuentros entre veraneantes y lugares estivales de moda. Otro metamensaje del narrador de $T T$ en voice over nos alerta y prepara a oír algo relevante del mismo generador

${ }^{5}$ Este detalle es significativo, deja en evidencia no sólo el arduo trabajo de selección de videos, sino el uso de algunos fragmentos de estos para crear el montaje que produce cada edición de $T T$. 
espontáneo de normalemas centrífugos: “Mientras se daba un baño, hizo esta reflexión”. Lo vemos zambullirse y ser filmado por otro turista-camarógrafo: “Las cosas más fantásticas casi siempre son gratis y hay que aprovecharlas porque bañarse en esta agua es gratis o sea. Puf! ¡Qué barbaridad! ¡Qué viva lo gratis!” (Fig. 6a, 6b). De su fértil inspiración, nace el meme de 2020: “QUÉ VIVA LO GRATIS”. Arriba a la izquierda, de tamaño discreto y escrito con una tipografía más leve e informal leemos el siguiente anuncio: \#1 TIRANOS ACONSEJA. Hemos presenciado así la génesis de esos signos cuyo destino es volverse virales, algo que efectivamente ocurre con los miles de visitantes al canal de YouTube de $T T{ }^{6}$

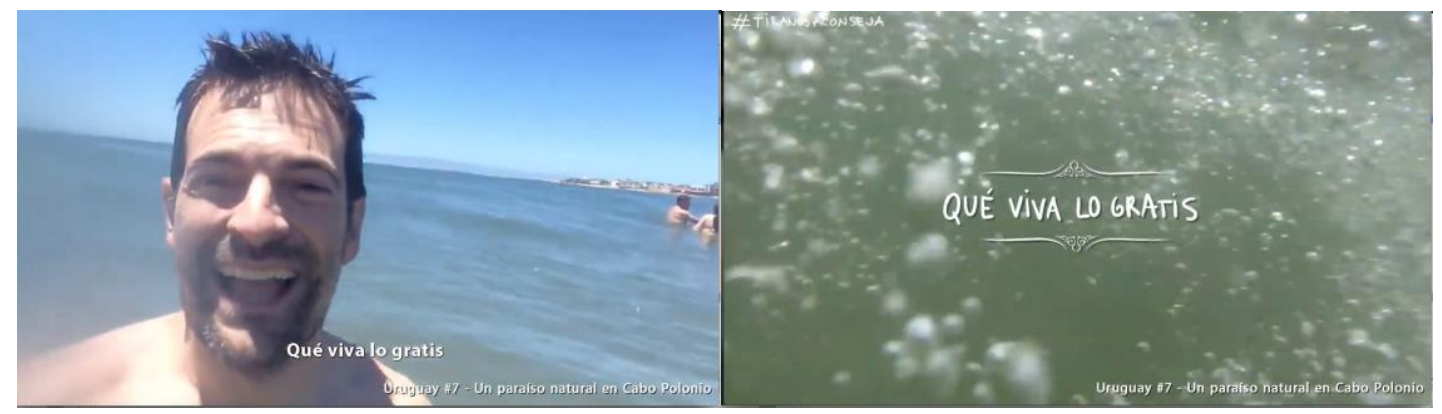

Fig. 6a, 6b "Las cosas más fantásticas...”; “iQué viva lo gratis!”

Más adelante, (5’35"), cuando otros turistas comentan que "es gratis ingresar para recorrer" un antiguo hotel del balneario Piriápolis, vemos reaparecer la muy ancha sonrisa de boca abierta, junto con la frase de 2020: “QQue viva lo gratis!" Se trata de un ejemplo emblemático de los recursos humorísticos y litóticos de TT, no sólo orales - siendo el principal la singular voz del narrador, además de la intervención hablada de aquellos que forman parte de la edición, como este joven y anónimo español - sino también la grafía utilizada. La escritura del consejo - \#1 TIRANOS ACONSEJA - insertado en un ángulo del meme se burla con característica suavidad del tipo de autoayuda que brinda el inmenso ejército de YouTubers. Esos signos completan el meme enmarcado gráficamente con elegancia, contra un fondo marino, para la posteridad. Entre los más de tres mil comentarios, cuando escribo este artículo, es apreciable la cantidad de visitantes que retoman y aceptan jugar con este meme instantáneo de TT. Para constatar su efectividad, uno de los elementos que hacen que esta serie web sea tan popular, cito algunos exemplos del meme así citado:

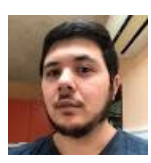

Matias Guillermo Yarad 1 month ago

${ }^{6}$ Cuando escribo este artículo, ya habían visitado el programa 367.011 personas. 
Estoy viendo este video gratis. Que viva lo gratis.

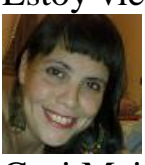

Ceci Maison

3 days ago

Que viva lo gratis!!!

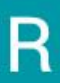

Rodrigo Molinari

5 days ago

Dos reflexiónes Q viva lo gratis es la mejor frase y nunca mejor dicho q peñarol es como la mugre

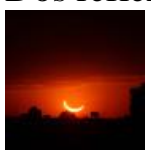

Miguel

5 days ago

Genial!!! Y que viva lo Gratis!!

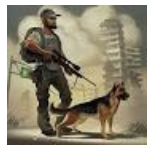

Draper CF

1 week ago (edited)

No entiendo como no tenes más subs. Mereces monetizar! Solo este video tiene más visitas que subscriptores! Media pila a la gente que ve los videos. Suscribirse es Gratis. Ya lo dice en el video hay que aprovechar todo lo gratis jaja

\section{N}

Natalia Saborido

1 week ago

GRACIAS POR TANTO!!!! que viva lo gratis!!!!

Entre las varias escenas de normalidad absoluta, cabe destacar la imagen de dos amigas sentadas sobre el pasto, dedicadas a mirar el mar y a disfrutar del hobby uruguayo por excelencia: "La gente compartía el mate". El uso del tiempo verbal imperfecto anticipa la pérdida de un bien, la añoranza por la felicidad ausente en pequeños actos de sociabilidad que conforman el corazón del imaginario social efectivo o instituido (Castoriadis, 1975). Como en un film catástrofe, hay una aposiopesis, es decir, se interrumpe el bucólico y monótono relato del curador de $T T$ por la irrupción de la pandemia: "paseaba por la rambla, disfrutaban de la playa pero de pronto, a mediados de marzo". Vemos un helicóptero cuya imagen se recorta contra el límpido cielo azul de marzo, y oímos una voz metálica amplificada que no se llega a entender del todo, salvo dos fragmentos: 'la emergencia sanitaria (...) debe abandonar el mismo y dirigirse a su domicilio'. Así instaló el régimen de la exhortación a la no movilidad 
el gobierno, en pandemia. De ese modo, se exhortó a dejar vacío un lugar ideal para correr, caminar, reunirse como lo es la muy extensa Rambla de Montevideo. "Entramos en cuarentena y por unas semanas las calles quedaron bastante vacías", agrega el narrador inútilmente, pues mientras lo dice, vemos de nuevo la visión aérea de la costa capitalina sin nadie en ella. Le lleva medio minuto retomar el ritmo habitual, y volver a mostrar a la gente que se refugió en su esfera íntima, dentro de sus casas, jardines o patios, para seguir con su vida, a pesar del régimen de excepción.

\section{CONCLUSIONES: LA ANOMALÍA SE ENFRENTA A LOS NORMALEMAS}

Si prestamos atención a los breves comentarios de seguidores de TT que expanden o explotan el meme construido por la serie para el resumen de 2020, no es difícil concluir que la elección de ese video de turista constituye un acto de reflexividad relevante, que es bien interpretado por algunos de quienes lo celebran en el canal de YouTube de TT. Desde su inicio, en diciembre de 2012, la creación de la serie web TT está rodeada de un aura de lo que es pura y absolutamente gratuito - en el sentido de ser una práctica, un acto creativo que no tiene otra explicación o justificación más que las puras ganas de hacerlo, sin pensar en efectos ulteriores o en beneficio práctico alguno. Se dice de algo que es 'gratuito' cuando es “arbitrario, sin fundamento", aporta el Diccionario de la Real Academia Española.

En las decenas de programas previos, $T T$ transgredió de modo consciente y consistente la noción de 'acontecimiento'; en su lugar, el relato narrado por Agustín Ferrando eligió para el montaje de la serie, videos que representan normalemas, unidades de normalidad elemental o básica en torno a la nación uruguaya. Ese material de archivo, el curador de la serie lo buscó gracias a muchas horas de exploración de la vasta bóveda audiovisual que es la red social mediática YouTube. Mi análisis procuró demostrar que, por primera vez, en el resumen del año 2020, la poética de TT no pudo no incluir un acontecimiento diametralmente opuesto a los típicos momentos triviales filmados que llamó de ese modo antojadizo, en su título desde 2012 hasta el presente. La declaración de pandemia del 13 de marzo de 2020 del gobierno uruguayo (Andacht 2020a) instauró un tiempo y espacio opuestos a los normalemas, como el que ocurre en la melancólica evocación del consumo del mate, de la bebida nacional, una práctica ritual central para la sociabilidad uruguaya. El hasta entonces inocente y celebrado acto de compartir la bombilla, la caña delgada y metálica que permite sorber el brebaje tradicional, se convirtió instantáneamente en la visión de lo prohibido: un modo de compartir la enfermedad circulante en el país. Un tabú impensado hasta esa fecha. 
Llego ahora al final de mi análisis sobre el fuerte impacto de un acontecimiento innegable en el flujo de normalemas o anti-acontecimientos que conforma la trama narrativa de $T T$ desde su creación hace casi una década. Para ello, retomo la primer frase que oímos y que proviene de un narrador anglófono y omnisciente en voice over: “¡Cuando miras el mapa, es fácil ver que el país Uruguay es una anomalía, no debería existir!” En efecto, 2020 fue el año de la gran anomalía, pero en lugar de ceder al temor reinante segregado por los medios sin cesar (Andacht, 2020c), y de aceptar el régimen de la Nueva Normalidad, con su infinidad de protocolos sanitarios, el curador-narrador de la serie de YouTube que explora la uruguayidad no nacionalista ni xenófoba (Andacht, 2017) en esa red mediática y social creó una trama vital que celebra la continuada vigencia de la normalidad a secas, que no es ni puede ser nueva o vieja.

Gracias al primer estornudo del niño Simón cuando ingresa por avión a Uruguay, y al regocijo de un turista vasco anónimo, $T T$ construyó una trama narrativa que ocurre para que se repita una escena, como escribe J. L. Borges, en el desenlace de su brevísimo relato "La trama". Sin negar ni ocultar el feroz golpe pandémico a la vida tal como la conocemos, y tal como la convirtió en artefacto literario durante todos estos años, la serie web concebida por Agustín Ferrando consiguió producir un relato admirable en el que la normalidad se declara victoriosa. La escena que reitera el resumen de 2020 concebido por TT es la del ser humano capaz de mirar más allá de este desafío y de hacerlo en base a signos tan triviales como los registrados y subidos a YouTube, sin que sus creadores originales y anónimos sepan que filman para que se arme otra escena, la de la victoria humana contra la adversidad llamada Covid-19.

\section{REFERENCIAS}

Andacht, F. (2020a). The manifold media representation of Covid-19: from helpless cuteness to uncanny threat. Degrés, 182-183 (1),1 - 13.

Andacht, F. (2020b). El nada discreto desencanto de la unanimidad. eXtramuros. La escritura ante el declive del debate público. No. 6, junio. https://extramurosrevista.com/el-nada-discreto-desencantode-la-unanimidad/

Andacht, F. (2020c). La agridulce y muy ancha grieta del kitsch pandémico.

Andacht, F. (2017). Nuevos Signos del Imaginario Mediático Latinoamericano: la serie uruguaya de YouTube Tiranos Temblad. En: Adilson Cabral et alii. (eds.) (2017). Nuevos Conceptos y Territorios en América Latina (pp. 371-390). São José dos Pinhais: Editorial Página 42 
Andacht, F. (1996). Paisaje de Pasiones. Tratado de las pasiones en Mesocracia. Montevideo: Fin de Siglo.

Castoriadis, Cornelius (1975). L’institution imaginaire de la société. Paris: Seuil.

Danto, A. C. (1981). The transfiguration of the commonplace. A philosophy of art. Cambridge, Mass.: Harvard University Press.

Dayan, D. y Katz, E. (1992). Media events. The live broadcasting of history. Cambridge, Mass.: Harvard University Press.

May, S. (2019). The power of cute. Princeton, N.J.: Princeton University Press.

Debrock, G. (1991). La información y el estatuto metafísico de los signos. Comunicación y sociedad. IV (1-2), 53-64.

Eagleton, T. (2003). Pork Chops and Pineapples. London Review of Books. Vol. 25 No. $20 \cdot 23$ October 2003.

Frochtengarten, F. (2009). A entrevista como método: Uma conversa com Eduardo Coutinho. Psicologia USP, São Paulo, janeiro/março, 20(1), 125-138.

Kermode, F. (1967). The sense of an ending. Studies in the theory of fiction. New York: Oxford University Press.

Real de Azúa, C. (1964). El impulso y su freno. : tres décadas de Batllismo y las raíces de la crisis uruguaya. Montevideo: Ediciones de la Banda Oriental.

Spitzer, L. (1945). La enumeración caótica en la poesía moderna. Trad. R. Lida. Buenos Aires: Facultad de Filosofía y Letras. Inst. de Filología/Casa Coni.

Sturrock, J. (1986). Goodbye to Borges. London Review of Books, Vol. 8 No. 14 · 7 August 1986 Wolf, M. (1991). La investigación de la comunicación de masas. Buenos Aires: Paidós.

\section{Videos}

TIRANOS TEMBLAD | ESPECIAL 2020. Subido a YouTube, 06.04.2021:

https://www.youtube.com/watch?v=bXO3qD-3qvU

How does Uruguay even exist? (es el video de dónde Agustín Ferrando extrajo el inicio del resumen de acontecimientos de 2020) https://www.youtube.com/watch?v=AzsCn_wKfbI 
Original recebido em: 10 de junho de 2021

Aceito para publicação em: 05 de julho de 2021

\section{Fernando Andacht}

Doutor em Filosofia (Dr. Phil), University of Bergen, Noruega, 1998; M.A. em Linguística, Ohio University; Lic. en Letras, Fac. de Humanidades \& Ciencias, Univ. de la República, Montevidéu. Bolsista Fulbright (1991) e da Fundação Alexander von Humboldt (1997-1998). Pesquisador Nível II,

Sistema Nacional de Investigadores ANII/Uruguai. Professor Titular, Diretor do Instituto de Comunicação/Facultad de Información \& Comunicación, Universidade da República, Montevidéu; Prof. do Programa de Pós-Graduação em Comunicação e Linguagens, Univ. Tuiuti do Paraná, Curitiba e no Doutorado em Semiótica da Universidad Nacional de Córdoba, Argentina.

\section{@(๑)(}

Esta obra está licenciada com uma Licença

Creative Commons Atribuição-NãoComercial-CompartilhaIgual 4.0 Internacional 